\title{
The self-regulation of teleological thinking in natural selection learning
}

\author{
Leonardo González Galli , Gastón Peréz² and Alma Adrianna Gómez Galindo 3**
}

\begin{abstract}
Background: Teleology is one of the critical aspects of students' intuitive concepts about living beings and, specifically, their evolution. This cognitive bias imposes a substantial restriction on the process of learning such content. In this work, we rely on epistemological, psychological and pedagogical analyses to substantiate an educational proposal centered on the concepts of epistemological obstacles and metacognitive vigilance.

Results: Based on Michael Ruse's epistemological analysis, according to which teleology in biology persists because the scientific explanation of adaptation necessarily involves appeal to the metaphor of design, and on research in cognitive psychology, especially in relation to metacognition and self-regulated learning, we argue that the primary educational aim must be to encourage students to develop metacognitive skills to regulate the use of teleological reasoning. We develop our instructional proposal based on the didactic concepts of epistemological obstacles and metacognitive vigilance (consistent with epistemological and psychological analyses).
\end{abstract}

Conclusion: We briefly discuss the instructional implications of our analysis and some possible relationships between our proposal and other lines of research in psychology and science education.

Keywords: Teleology, Epistemological obstacle, Metacognitive vigilance, Teaching of evolution

\section{Introduction and purpose}

Despite the consensus on the importance of all citizens learning evolutionary biology, especially the theory of natural selection (Kampourakis 2014; Miller-Friedmann et al. 2019; WGTE 1998; Wilson 2007), there is substantial evidence from the last 40 years from different countries suggesting that most high-school graduates have an insufficient understanding of these topics (Smith 2010a, b). Even worse, this conclusion applies to many teachers and undergraduates as well (Gresch and Martens 2019; Nehm and Schonfeld 2007; Sickel and Friedrichsen 2013). Among the many factors responsible for these poor educational results, the inconsistency of intuitive conceptions of evolutionary processes with the currently

\footnotetext{
*Correspondence: agomez@cinvestav.mx

${ }^{3}$ Unidad Monterrey, Cinvestav, Vía del conocimiento 201, Km. 9.5

Carretera nueva al aeropuerto, Parque PIIT, Apodaca, Nuevo León 66600, México

Full list of author information is available at the end of the article
}

adopted scientific theories has been stressed (Kampourakis 2014; Settlage1994; Smith 2010b). These conceptions have proven to be highly resistant to change through education. Analyses of these conceptions have shown that teleology is a central assumption of intuitive thinking about living beings in general, and evolution in particular (González Galli and Meinardi 2011; Kampourakis and Zogza 2008; Kampourakis et al. 2012; Haydock and Arunan 2013; Lennox and Kampourakis 2013; Sinatra et al. 2008). Many students assume that in nature, everything exists and occurs to achieve a predetermined purpose (often, that purpose is survival). Therefore, students tend to claim, for example, that "bacteria mutate in order to become resistant to the antibiotic" or that "polar bears became white because they needed to disguise themselves in the snow."

In this work, we consider a group of arguments that include the notion of the end, goal or purpose in their structures as teleological arguments (Allen et al. 1998a;

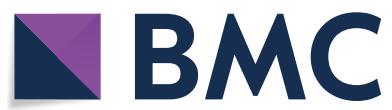

(c) The Author(s) 2020. This article is licensed under a Creative Commons Attribution 4.0 International License, which permits use, sharing, adaptation, distribution and reproduction in any medium or format, as long as you give appropriate credit to the original author(s) and the source, provide a link to the Creative Commons licence, and indicate if changes were made. The images or other third party material in this article are included in the article's Creative Commons licence, unless indicated otherwise in a credit line to the material. If material is not included in the article's Creative Commons licence and your intended use is not permitted by statutory regulation or exceeds the permitted use, you will need to obtain permission directly from the copyright holder. To view a copy of this licence, visit http://creativeco mmons.org/licenses/by/4.0/. The Creative Commons Public Domain Dedication waiver (http://creativecommons.org/publicdomain/ zero/1.0/) applies to the data made available in this article, unless otherwise stated in a credit line to the data. 
McLaughlin 2003). As part of this "family of notions," we also examine the idea of functionality (McLaughlin 2003; Nagel 1961; Sterelny and Griffiths 1999). Many forms of reasoning, such as anthropomorphism or needbased reasoning, are related to teleological assumptions. Although we do not ignore the differences among these forms of reasoning (for instance, that anthropomorphism usually includes an intentional assumption that may be absent in many cases of need-based reasoning), we suggest that they all involve teleological assumptions.

In different studies on the role of students' teleological reasoning, it is unequivocally assumed that such reasoning is incorrect (e.g., Settlage 1994). Additionally, it is suggested that the primary educational aim is for students to abandon this form of reasoning. In this sense, Settlage (1994), after characterizing explanations proposed by students as "teleological" and "Lamarckian," states, "Although students may possess unscientific explanations for the phenomena, a substantial force is required to displace their notions."

Eliminating teleology would promote the construction of knowledge that is more similar to scientific theories that, presumably, would not be teleological in any sense. In recent years, this strict attitude, which we may call "eliminative", has been partially reviewed, and different authors have acknowledged that teleological thinking may have heuristic value (Gresch and Martens 2019; Jungwirth 1975a, b; Tamir and Zohar 1991; Zohar and Ginossar 1998). Recently, the idea that eliminating teleological thinking is impossible has been gaining support. However, although teleological thinking cannot be eliminated, it must be addressed in one way or another, because it causes substantial difficulties in understanding biology, especially the theory of evolution (Evans 2018).

In reference to the problem being posed (how to deal with the teleological thinking of students in the teaching of evolution), the purpose of this work is to present the foundations of an educational perspective on students' teleological conceptions based on the notion of epistemological obstacles and metacognitive vigilance. These concepts have been developed mainly by Frenchspeaking science education researchers (Astolfi 1997a, b; Astolfi and Develay 1989; Peterfalvi 1997). We adopt this theoretical framework mainly because we consider the concept of epistemological obstacle to be especially useful for characterizing the role that a reasoning style, such as intuitive teleological thinking, has in the teaching processes -see later in this section- (González Galli and Meinardi 2011). By "epistemological obstacle", we mean intuitive ways of thinking that are transversal (they have a certain degree of generality and can be applied to topics of different domains) and functional (they fulfill an important cognitive function, including heuristic, predictive and explanatory) and that can potentially interfere with learning about a scientific theory (González Galli and Meinardi 2015). As we will discuss later, the obstacle can promote thinking about certain topics while, at the same time, biasing and limiting thinking about that topics. From this perspective, the main learning goal is students' development of "metacognitive vigilance," which refers to a sophisticated ability for the regulation of teleological reasoning. Components of this ability, such as knowing what teleology is, recognizing its multiple expressions, and intentionally regulating its use, are detailed below.

The findings and recommendations of French science education researchers (on whose research we base our work) are consistent, to a certain extent, with those derived from important lines of research in the science education literature published in English. For example, according to Schraw (1998), "metacognitive awareness" includes three forms of awareness: declarative (refers to knowing "about" things), procedural (refers to knowing "how" to do things), and conditional knowledge (refers to knowing the "why" and "when" aspects of cognition). We can consider these three components of cognitive awareness analogous to the three components of metacognitive vigilance that we have defined below. For their part, authors in the field of cognitive psychology (for example, Gelman and Williams 1998 or Talanquer 2009) define "cognitive constraints" as elements of a knowledge system that guide and facilitate cognitive processes but, at the same time, they restrict and bias them. In this sense, this concept is analogous to that of epistemological obstacle.

We prefer the term epistemological obstacles instead of cognitive restrictions because the concept of obstacle is a strictly didactic one. In this sense, the obstacle is defined from the interaction between some style of reasoning, and the scientific theory to be learned (the third component of the definition we outlined earlier). In contrast, the idea of cognitive constraint is more linked to the experimental cognitive psychology approach. Thus, the obstacle concept has a more pragmatic and contextually situated nature than that of cognitive constraint. For this reason, we will use the terminology of the French authors.

Our proposal is also based on our questioning of the epistemological assumptions underlying the views that all forms of teleology should be eliminated or censored in the teaching of biology. Concerning the question of epistemology, following Ruse (2000, 2003, 2008), we assume that reasoning based on the theory of evolution by natural selection implies a certain form of teleology.

In this paper, we initially review the epistemological problem of teleology in biology. We address this matter in depth since the assumptions related to how biology 
should be taught strongly depend on how the key question related to the role and legitimacy of teleology in this science is answered. Then, we briefly present the psychological foundations of our proposal, as well as the main antecedents in the research on the teaching of evolutionary biology and students' teleological conceptions. Later, we analyze the educational implications of this epistemological and psychological analysis, especially related to the role of students' teleological concepts in learning of biology, mainly natural selection. Based on these analyses, we present an educational proposal focused on students' development of metacognitive vigilance in relation to teleological reasoning. Last, we briefly analyze the relationship between our proposal and the theoretical framework of conceptual change and the dual processing of information.

\section{The problem of teleology in biology: epistemological aspects}

In the West, explanations of the natural world by Plato and Aristotle included teleological assumptions (Allen et al. 1998b). However, the worldview resulting from the Scientific Revolution questioned the validity of teleological notions ${ }^{1}$ (McLaughlin 2003). The reasons why teleological explanations are not considered valid from a scientific point of view are as follows (Ruse 2003): (a) historically, they have been associated with religious perspectives, including supernatural assumptions, that were in opposition to the metaphysical bases of the sciences; (b) they seem to imply a temporary inversion of cause and effect that is incompatible with the classical notion of causality; and (c) they seem not to adjust to what, according to logical positivism, would be the ideal scientific explanation, i.e., the nomological deductive model or the "covering law" model.

Despite the rejection of teleology that was consolidated after the Scientific Revolution, biologists never completely abandoned teleological reasoning and expressions, even though they often stated that their science did not include such explanations (Mahner and Bunge 1997). As we mentioned, pre-Darwinian natural history included teleological explanations of various types, but in that context, it was not problematic because it was assumed that all creatures were part of a divine plan. Darwin's provision of an alternative naturalistic explanation to divine design to explain the adaptive nature of living beings (the "biological design") through the theory of natural selection was often interpreted as Darwin's triumphant expulsion of teleology from biology (Mayr 1991). Nonetheless, this interpretation is debatable because it arbitrarily restricts the meaning of "teleology." In general, authors who state that Darwin eliminated teleology from biology, such as Ghiselin (2003), refer to the fact that the theory of natural selection rendered references to a divine design unnecessary to explain complex adaptation and that the theory questioned the idea of evolution having a predetermined directionality. We agree that Darwin's theory had such beneficial effects on biology. However, teleological language and explanations persisted in biology. What we refer to here as "the problem of teleology in biology" thus refers to the fact that biology retained teleological explanations and notions even after Darwin offered a naturalistic explanation of "biological design". These considerations suggest that Darwin eliminated some forms of teleology, but not all.

In summary, after Darwin, naturalists were able to abandon the divine design hypothesis, but they continued to use teleological expressions and explanations. Therefore, even if biologists have often stated that they reject all forms of teleology (see Hickman et al. 2008; Futuyma 2009) because they consider them scientifically illegitimate, biologists have never eliminated all teleological reasoning and expressions. This contradiction (Dennett 2017; Jacob 1993; Mahner and Bunge 1997) sheds light on a critical problem regarding the philosophy of biology. Considering this ambiguous situation, some authors (Lorenz 1982; Mayr 1988; Pittendrigh 1958; Simpson 1964; Williams 1966) have suggested the use of the term "teleonomy" to refer to scientifically acceptable forms of teleology. However, we agree with Ruse (2003) in that a mere terminological change does not resolve the conceptual problem, and in fact, the notion of teleonomy, defined as a directedness towards goals due to the operation of a program, ${ }^{2}$ is clearly teleological (Lennox 1993; Mahner and Bunge 1997). In fact, the idea of operating a program is based on a computing metaphor (GodfreySmith and Sterelny 2008) and implies the existence of a programmer. Moreover, it is possible that the introduction of the concept of teleonomy further complicates analysis of the role of teleology in biology (Ayala 1970) by generating the illusion of avoiding teleology, thus obscuring an essential aspect of some forms of reasoning in biology.

The epistemological foundations of our proposal are based on Michael Ruse's analysis of this problem (2000,
${ }^{1}$ For more information on the different forms of teleological thinking throughout the history of the West, see Lennox and Kampourakis (2013).
${ }^{2}$ In this context, Mayr (1988, p. 49) defines a program as "coded or prearranged information that controls a process (or behavior) leading it toward a given end". 
2003, 2008). According to this author, teleological explanations and terminology continue to be used in biology because in the analysis of adaptive traits, the metaphor of design is employed. According to Ruse, the metaphor of design, which represents organisms and their parts as if they were products of deliberate design, will always be an obligatory resource for constructing explanations of adaptation based on the theory of evolution by natural selection. Thus, although teleological expressions are absent in more technical scientific explanations of adaptation, the construction of such explanations previously required viewing organisms as if they were objects of design, which has evident teleological connotations.

\section{Legitimizing teleology in biology}

Given the already mentioned continuation of teleological expressions and reasoning after Darwin, many biology philosophers (Arriew 2007; Dennett 2017; Ruse 2003; Sober 2000) have concluded that Darwin did not eliminate teleology from biology but that he naturalized it. ${ }^{3}$ This perspective implies accepting that teleology bears a legitimate place in biology.

In general, the three objections to teleology are derived from an epistemological stance associated with logical positivism or schools of thought related to it, such as the received view (Ruse 2003). These epistemological approaches were physicalist in the sense that they analyzed all sciences in light of an ideal science: classical physics (Mayr 2004; Stamos 2008). However, later developments in the philosophy of science in general and the rise of the philosophy of biology in particular tended to question this approach (Mayr 1997, 2004). Therefore, there is a tendency to recognize that the different sciences have epistemological characteristics that make them unique and different from physics (Mayr 1997, 2004; Ruse 2008). The transition from a normative philosophy of the sciences (specifically concerned with how sciences should be) towards a naturalistic philosophy of the sciences (concerned with what sciences actually are) enabled the recognition of the specific epistemological characteristics of biology.

\footnotetext{
${ }^{3}$ It is important to clarify that the recognition of the teleological nature of questions about adaptation, much like that of their answers based on natural selection, does not imply any acknowledgment or acceptance of "scientific creationism" or its latest version, the "intelligent design theory." Some of the cited authors, such as Dennett (2017), support the notion of design, while others, such Dawkins (1996), assert that organisms are "designoid objects", but this is an entirely naturalistic design concept. Both "scientific creationism" and the "intelligent design theory" are clearly religious movements, and therefore, their ideas should have no place in the teaching of biology (Branch and Scott 2009).
}

In regard to the first objection (i.e., the apparent association between teleology and supernatural events), it is clear that the forms of teleology that have been retained biology have no supernatural characteristics (Brandon 1990; Arriew 2007). Dennett (2017) states that, in fact, there is design and purpose in the natural world, but that the design and purpose can be explained in a totally naturalistic way by natural selection. In this sense, Lennox and Kampourakis (2013) clearly distinguish, on the one hand, a form of teleology dependent on the idea that the world is the product of a supernatural creator and, on the other hand, a kind of teleology that assumes that in the world, there are systems oriented towards a purpose. This second view of teleology, related to the notion of adaptation, corresponds to Aristotle's worldview and Darwin's theory. More recently, Kampourakis (2020) distinguishes "design teleology" (which is "external" when the existence of an entity is explained from the intentions of an external agent, or "internal", when it is explained from the intentions of the same entity) of "natural selection teleology" (when the existence of a trait is explained from a natural process, due to the advantage that said trait confers on its owners).

Regarding the second objection (i.e., the alleged inversion of cause and effect), it is not evident that a good scientific explanation must necessarily be based on the identification of the efficient causes responsible for the phenomenon to be explained. In fact, explanations based on natural selection represent a form of teleological explanation and, as such, do not entail the identification of efficient causes (Ayala 1970). In any case, concerning the second objection, the teleological explanations that continue to exist in biology do not imply that present events are caused by future events (Brandon 1990; Nagel 1961).

Last, for the third objection related to the non-adjustment of teleological explanations to the covering law model, it is currently considered that this model cannot account for all the types of explanations offered by the different sciences. In particular, the model seems to be especially inadequate for some of the biological explanations (Kleiner 2003; Sober 2006; Stamos 2008).

\section{The teleological nature of explanations based on natural selection}

In relation to the previous discussion, many authors have argued not only that teleology currently has a legitimate role in biology but also that explanations based on natural selection represent a particular form of teleological explanation or, at least, that their formulation necessarily implies resorting to a teleological perspective at some 
point in the process. Although this perspective may seem slightly heretical at first glance (especially for biology teachers and biologists), in recent years, many biology philosophers (Brandon 1981; Lennox 1993, 1994; Lewens 2000, 2004; Ruse 2000, 2003; Short 1983, 2002; Walsh 2000, 2006) have arrived at this conclusion (Lennox and Kampourakis 2013). Among these authors, Michael Ruse's analysis $(2000,2003,2008)$ is relevant to our educational interests.

According to Ruse, teleology is present in biology as a result of biologists using the metaphor of design to understand the origin of living creatures and their parts. For example, if we look at the color of a grasshopper and ask ourselves what it appears to have been designed for, this question would lead us to create hypotheses such that the color of the grasshopper appears to be designed to hide the insect from its predators. This metaphorical cognitive exercise would allow us to generate hypotheses on the adaptive value of those traits. If the evidence subsequently obtained confirmed any of these hypotheses, we would move on to propose an explanation based on selection. In the most technical versions of these explanations, there would be no teleological expressions. So, in grasshopper example, explanations of the cryptic coloring would be based on certain prior conditions (heritable color variations, predators that use their sight, etc.), and they would show that the current trait (i.e., the cryptic coloring) represented an expected consequence of that condition. With that in mind, Ruse argues that although no teleological expressions are present in this explanation, we would be able to come up with this hypothesis only if we first imagined the trait whose evolution we wished to explain as if it had been designed. It is important to stress that for Ruse, the use of this metaphor is not optional but compulsory: we could not use natural selection to explain evolution without using that metaphor. This response proposed by Ruse is compatible with and converges with other analyses (see Dennett 1989, 1995, 2017, on the concept of the "intentional stance" and Lewens 2000, 2004, on the concept of the "artifact model"). In accordance with these analyses, teleological expressions used by biologists are not just a simple manner of speech (as proposed by authors such as Ghiselin 1994) but evidence of a teleological reasoning style.

According to these authors' proposals, teleology is directly linked to the construction of explanations about adaptive traits based on natural selection. This suggestion implies that, for instance, teleological reasoning would have no place in cases in which the evolution of a trait is explained by a nonselective process, such as genetic drift. Therefore, biology would only include teleological reasoning insofar as it maintains the concept of adaptation. In light of this observation, we could suggest that apart from the known criticism of "adaptationism," it is difficult to imagine a version of biology that would eliminate the notion of adaptation. In any case, this concept still currently plays a fundamental role in biology. ${ }^{4}$ This claim is also valid for the notion of function that, as we have already mentioned, has teleological implications as well (McLaughlin 2003).

Acknowledgment that, in some instances at least, biologists employ teleological expressions and reasoning does not imply that they deem all kinds of teleology to be acceptable. For example, no biologist would say that "bacteria mutated in order to become resistant to the antibiotic" or that "the great dinosaurs went extinct so that mammals could diversify, and as a result, humans could evolve." All biologists are aware that teleological expressions such as those mentioned above are wrong from the point of view of the theory of natural selection. Nonetheless, they allow themselves to make statements such as the following: "Each sperm is a stripped-down package of highly condensed genetic material designed for the single purpose of reaching and fertilizing an egg" (Hickman et al. 2008, p. 139); "Parthenogenesis is surprisingly widespread in animals (...) It may have evolved to avoid the problem-which may be great in some animals-of bringing together males and females at the right moment for successful fertilization" (Hickman et al. 2008, p. 141); and "Clots are not permanent structures but are designed to dissolve when the structural integrity of damaged areas is restored" (Berg et al. 2015, p. 307-308). These expressions taken from university textbooks are clearly teleological. As we have pointed out, it is common for biologists who use these expressions to simultaneously completely deny the legitimacy of teleology. For instance, Hickman et al. state, "An argument that nature has a predetermined goal, such as the evolution of the human mind, is termed teleological. Teleology is the mistaken notion that the evolution of living organisms is guided by purpose toward an optimal design. A major success of a Darwinian evolutionary theory is its rejection of teleology in explaining biological diversification" (Hickman et al. 2008, p. 14). If we define "teleology" in this way, we should all agree that teleology should be rejected, and that Darwin eliminated it from science. However, as we have already pointed out,

\footnotetext{
${ }^{4}$ The classical criticism of adaptationism can be found in Gould and Lewontin (1979). A defense of the adaptationist program can be found in Dennett (1995, chapter 9). Gould and Lewontin's antiadaptationist attitude have had a significant impact on the educational community, which has led to many teachers distrusting the concept of adaptation. Thus, we cite the words of Lewontin (1978: 230): “(...) to abandon the notion of adaptation entirely, to simply observe historical change and describe its mechanisms wholly in terms of the different reproductive success of different types, with no functional explanation, would be to throw out the baby with the bathwater. Adaptation is a real phenomenon. It is no accident that fish have fins, that seals and whales have flippers and flukes, that penguins have paddles and that even sea snakes have become laterally flattened".
} 
it is arbitrary and contrary to the uses of the term in the philosophical literature to give the term "teleology" such a restricted meaning.

We believe that the way to avoid these contradictions is to acknowledge that teleology can take on multiple forms (see Ayala 1970, Kampourakis 2020 or Mayr 1988) and that only some of these forms are scientifically acceptable. We suggest that, in fact, biologists do acknowledge and use acceptable forms of teleology, even those biologists who state that teleological reasoning should not be used, such as those quoted above. As was previously mentioned, biologists deem as legitimate only those teleological expressions that are compatible with approved scientific theories, especially with the theory of natural selection. Therefore, it is not that biologists do not use teleological reasoning and terms but that they use them properly, i.e., they regulate their use based on their sound knowledge of the theory of natural selection.

We maintain that the epistemological perspective of the problem of teleology in biology we have outlined in this section, mainly based on Michael Ruse's analysis, is especially suitable for our educational concerns for two reasons. First, unlike views that censor all kinds of teleology, this approach takes into consideration the undeniable fact that biologists frequently employ teleological expressions. We suggest that this naturalistic perspective (in opposition to the normative perspective) contributes to the development of a richer and more sophisticated image of science than the perspective based on a physicalist philosophy of the sciences. In this sense, this approach contributes to students' recognition of the epistemological singularity of biology (i.e., the design metaphor resource), promoting an understanding of the fact that the different sciences use different styles of explanation that are appropriate for their specific goals. In this vein, Ruse's proposal also enables us to value the role of metaphors in the sciences (Aubusson et al. 2006; Bradie 1999), which is a topic of great interest for understanding the nature of science. Moreover, analyzing the role that the design metaphor plays in evolutionary biology sheds light on the hypothesis creation process, which is an aspect that is overlooked by philosophy of the sciences, which distinguishes the "context of discovery" from the "context of justification", declaring that the former is more of a problem of psychology than of the philosophy of the sciences (Schickore 2018). Therefore, analyzing the role that the design metaphor plays allows for an argument regarding the creative process of hypothesis generation, which is a neglected matter in education, as education is always more concerned with experimentation and other aspects related to justifying a hypothesis. Second, acknowledging the legitimacy of teleology in biology allows us to give value to students' cognition based on the assumption that students' intuitive styles of reasoning are not flawed in absolute terms and that they should therefore not be abandoned, but rather critically and consciously revised, with a consideration of scientific theories, as circumstances may require. In that sense, we value the possibility of discussing with students the fact that scientists use, at least in some instances in the investigation process, the same reasoning styles that we all use (Giere 1988).

\section{The problem of teleology in biology: psychological aspects}

In recent years, numerous investigations into intuitive teleological thinking in the field of cognitive psychology have been of great relevance for educational issues (Coley and Tanner 2012; Gelman and Rhodes 2012; Inagaki and Hatano 2006; Keil 1994; Kelemen 1999a, 2012). According to these investigations, teleological reasoning is a central component of intuitive thinking about human behavior and artifacts and plays an important role in everyday life (Coley and Tanner 2012).

It can be assumed that there are several factors that explain the existence of this teleological cognitive bias. Among these factors is the incorrect use of teleological expressions in formal and informal instruction, including the type of explanations that parents give to children's "why" questions. More general factors are related to religious beliefs or the type of discourse on nature most frequent in media. However, in addition to these factors, there is strong evidence that such bias is generated from a biologically-based cognitive structure (Kelemen 2012). This teleological bias seems to be present from the first months of life (Kelemen 1999b; Legare and Gelman 2008) and, at least to some extent, to be universal (that is, it is probably present in all cultures) (Schachner et al. 2017; Rottman et al. 2016). According to Kelemen (1999a), young children apply teleology to a wide range of phenomena ("promiscuous teleology"). Children use teleological reasoning not only to account for biological phenomena but also to explain other phenomena related to inert objects by stating, for example, that mountains exist so that humans can climb them. Subsequently, the range of application of teleological reasoning is restricted but persists in adulthood in relation to the biological domain (Kelemen 1999a, Kelemen et al. 2013). While some authors (Carey, 1995) have argued that teleological bias disappears during development (being replaced, after a process of conceptual change, by more mechanistic approaches), the evidence seems to suggest that such bias persists as a default reasoning style (Kelemen et al. 2013).

These considerations are of great importance to rethink the role of teleological intuition in teaching. They suggest 
that it is expected that this cognitive bias will be encountered at all educational levels and that the understanding of many scientific models will be hindered by this cognitive bias. However, it is also inferred from these analyses that it is unreasonable (or undesirable) to attempt to eliminate such bias. As we show in the section on epistemological issues, teleological reasoning is present even in academic biology (Ruse 2000; Mahner and Bunge 1997). Kelemen et al. (2013) show that this bias persists even in physical science professionals. These findings lead us to propose the hypothesis that scientists have not abandoned teleological reasoning but, in some way, manage to regulate it so that it does not interfere negatively with their reasoning based on the scientific models they use to generate explanations. This regulation could involve not using teleological intuitions at all (for example, when explaining the movement of the stars) or using them in an appropriate way (for example, when explaining biological adaptations).

\section{The problem of teleology in biology: pedagogical aspects}

The teleological character of many of the conceptions that students have about evolution is one of the most robust research findings on teaching and learning evolutionary biology (Anderson et al. 2002; Bardapurkar 2008; Bartov 1981; Bishop and Anderson 1990; Kampourakis 2014; Settlage 1994). This type of conception has been detected in students of all ages in many culturally diverse countries. Moreover, these conceptions are frequent even in biology professors and people with university studies in science (Gresch and Martens 2019; Kallery and Psillos 2004). Despite the different strategies posed from science education, these conceptions remain preset in students' discourse. A great diversity of ideas about evolution share a general teleological assumption. Thus, for example, it is common for students to believe that adaptation is the product of an individual transformation aimed at increasing the adjustment of the organism for its environment or that evolution has a certain intrinsic directionality.

The theoretical structure of the assumptions that underlie this diversity of conceptions is not clear, beyond the common general assumption that natural processes are oriented towards certain ends. One possible way to classify the types of teleological explanations of students in relation to evolution is to distinguish three main types of explanations (Gregory 2009; Kelemen 2012): (1) "basic explanations based on the idea of function", (2) "basic explanations based on the idea of necessity" and (3) "elaborate explanations based on the idea of necessity". The first two are the least elaborated in terms of their causal assumptions: no reference is made to identify causal factors. In contrast, in the case of "elaborated explanations based on the idea of necessity", the student resorts to a theoretical framework that is more consistent with a mechanistic approach, but in general, the explanations are not consistent with Darwinian explanations.

From these investigations, a set of suggestions has been derived concerning how to take into account the teleological conceptions of students in teaching. Of course, these suggestions are diverse due to the different theoretical frameworks adopted by the different authors. Thus, authors who adopt the framework of conceptual change have emphasized the need to confront students with empirical problems and evidence that question their conceptions (see, for example, Kampourakis 2014). Other authors have emphasized the need to increase students' conscious knowledge in relation to their teleological cognitive biases as well as to distinguish teleological explanations from other types of explanations (Bartov 1981).

Research has also shown that many teachers hold teleological conceptions (as part of what many authors call "Lamarckian conceptions") and that in many cases they do not recognize the problems associated with these conceptions (Sickel and Friedrichsen 2013). These findings are important and suggest the need to take this issue into account in teacher training (Gregory 2009). This is because the type of educational work necessary for students to learn evolutionary biology requires teachers with a high degree of knowledge (about evolutionary biology and about meta-scientific topics such as the debate on teleological explanations) and great metacognitive ability concerning their own conceptions so that they can regulate their own discourse and class discussions on teleology.

\section{Educational proposal}

Based on our previous epistemological and psychological analyses, we propose that the main educational objective is students' development of metacognitive vigilance on teleological obstacles. From a pedagogical perspective, our proposal is based on two main theoretical frameworks: epistemological obstacles (Astolfi 1997a) and metacognition (Peña Ayala 2015; Zohar and Dori 2012). The latter framework is closely related to that of selfregulated learning (Boekaerts 1999; Zimmerman 2000; Schraw et al. 2006). In the following sections, we briefly develop these theoretical frameworks and apply them to the case at hand.

\section{Teleological thinking as an epistemological obstacle}

In other works (González Galli and Meinardi 2011, 2015), we have characterized teleological thinking as an epistemological obstacle (Astolfi 1997a; Astolfi and Develay 1989). This concept seems particularly appropriate to consider the nature and function of teleological thinking 
from a teaching perspective. As noted in the Introduction, epistemological obstacles are transversal and functional styles of reasoning that constitute possible sources of difficulty in learning specific content. Nevertheless, authors who developed this theoretical framework state that obstacles are ambiguous (Astolfi 1997b). This ambiguity is generated from styles of reasoning that allow and encourage thinking about a specific topic (a positive effect) but, at the same time, bias and limit thinking (a potentially negative effect). Thus, in contrast to what the term "obstacle" suggests, its cognitive function is not purely negative.

In relation to negative aspects, the teleological obstacle may lead to misconceptions about evolution. Thus, for example, students tend to think that the production of genetic variations is geared toward producing adaptive changes. In the same vein, they may believe that the evolutionary process as a whole follows predetermined paths. Some students might even think that there is some form of intentionality involved in the evolutionary process.

However, and this is perhaps less obvious, the teleological obstacle has positive effects in relation to learning the theory of natural selection. Specifically, the teleological obstacle gives rise to intuitions that, according to Ruse (2000, 2003, 2008) and Dennett (1995, 1989, 2017), are essential to explain adaptations employing the natural selection theory. In this sense, teleological reasoning suggests questions such as, "How does having those colors benefit the butterfly? Is it that it allows it to camouflage with the surroundings and avoid predators?" These questions and their possible answers are clearly teleological. Nonetheless, this is how scientific hypotheses are generated in the adaptationist program. Then, similar to biologists, students create an explanation of how the trait being analyzed evolved, which must be coherent with scientific theory. Furthermore, to the extent that they focus on the study of the theory of evolution, students should be able to understand teleological questions such as, "How does trait X benefit its holder?" This question could be answered, "In no way", given that the trait being analyzed might not be a product of natural selection. In other words, part of the metacognitive ability of an advanced student would include knowledge that teleological reasoning and language should be restricted to those cases in which one decides to adopt an adaptationist approach.

\section{Metacognition and self-regulated learning: the development of "metacognitive vigilance" on teleological thinking}

Although there is no single definition of metacognition (see, Gunstone and Mitchell 2005; Hacker et al.
2009; Peña-Ayala and Cárdenas 2015; Veenman 2012; Zohar and Barzilai 2013; Zohar and Dori 2012), it can be defined as the subject's knowledge and control over his or her thinking and learning (Cross and Paris 1988). There is usually a differentiation between metacognitive knowledge and metacognitive regulation (Dye and Stanton 2017; Schraw et al. 2006). While metacognitive knowledge refers to what we know about our thinking, metacognitive regulation refers to how we control our thinking and learning. More specifically, metacognitive knowledge would be declarative knowledge about the interrelationships between the subject, the task to be performed, and the strategies to be used. Metacognitive regulation would include the ability to monitor, guide, control and manage one's learning and behavior during the problem solving (Veenman 2012). The relationships between the two components of metacognition (knowledge and regulation) are complex, and evidence suggests that the possession of knowledge does not guarantee the ability to regulate cognition.

As we have already pointed out, the metacognition framework is closely related to that of self-regulated learning (Boekaerts 1999; Schraw et al. 2006). The latter suggests that the subject becomes a self-regulated learner through a gradual process that involves four levels: observational (focused on modeling), imitative (focused on social orientation and feedback), self-controlled (focused on building internal standards of what is an acceptable performance and development based on these standards) and self-regulated (focused on the subject's strong beliefs about self-efficacy and rich repertoire of cognitive strategies that allow self-regulation of learning). Thus, this development implies a passage from performance strongly supported by external social factors to performance based on internal cognitive tools (Schraw et al. 2006). According to Schraw et al. 2006, self-regulated learning has three components: cognition, metacognition and motivation. Cognition refers to the abilities to encode, store and retrieve information. Metacognition refers to the subject's ability to understand and monitor his or her cognitive processes, and motivation is related to beliefs and attitudes that affect the use and development of cognition and metacognition. Another aspect of self-regulated learning that is important for our proposal is that the subject must perceive that there are different alternatives to choose from (Boekaerts 1999), in our case, in relation to the type of explanations that can be constructed to account for a biological phenomenon.

In the teaching approach that we propose, the aim would not be for students to completely abandon the use of teleology but rather to be able to use it properly, as biologists do, and to consciously regulate the use this type of reasoning as much as possible. Students should 
be able to depend on natural selection theory to assess which teleological explanations and expressions are acceptable and which are not. In this sense, for instance, it could be considered that the phrase "gazelles evolved in order to be faster and thus avoid their predators" could, under a specific interpretation, be acceptable, whereas the statement "gazelles mutated to become faster" would never be acceptable. The former expression is ambiguous and could be expressing a mistaken idea (suggesting that the genetic variation needed was directionally caused) or a correct idea (suggesting the reason why the fastest variant increased its population frequency). Those readers who deem the first expression unacceptable should remember that these types of expressions are used frequently by professional biologists and, as we have shown, can be found in university textbooks.

In any case, we consider the censorship of teleological language in the classroom does not facilitate the learning process (Zohar and Ginossar 1998). There is broad consensus on the need for students to make their ideas explicit in class. This is a necessary condition for the conceptual review required for the learning of scientific theories. Therefore, the censorship of teleological thinking (which generally translates into the expression “don't say 'in order to"') tends to hide what students think, hindering their learning experience. Our proposal focuses on generating frequent instances of explicit discussion about the meaning of teleological expressions that arise in class. These discussions provide the framework in which a theory (the theory of natural selection, in this case) can be reviewed to discuss which expressions are acceptable and which are not.

\section{A general proposal to address the problem of teleology in the teaching of evolutionary biology}

The primary learning aim of our proposal is for students to gain awareness of their own teleological biases and develop a specific ability for the regulation of that aspect of their cognition. Therefore, the goal is related to promoting the development of students' metacognitive knowledge and regulation, i.e., their performance as selfregulated learners, in connection with the teleological obstacle. To accomplish this, the literature on epistemological obstacles provides useful suggestions consistent with the frameworks of metacognition and self-regulated learning.

According to Astolfi and Peterfalvi (1997), some essential aspects of educational work are (a) the destabilization of the obstacle, (b) alternative (re)construction, and (c) identification. Destabilization refers to the process of students becoming aware of the obstacle's limitations through the use of resources, such as contrasting conflicting empirical evidence. The so-called sociocognitive conflict that arises from noticing the coexistence of multiple points of view, which are sometimes mutually exclusive, also contributes to weakening students' confidence in the obstacle. For example, in the case of teleological reasoning and learning the theory of natural selection, the fact that the frequency of occurrence of a mutation is independent of whether the mutation has positive or negative effects for the organism could contribute to reducing the student's confidence in teleological reasoning (see Kampourakis 2014 for other suggestions in this line). Alternative (re)construction refers to the contribution by the teacher of an alternative explanatory framework concerning the obstacle that proves to be more coherent than the student's scientific perspective. Continuing with the previous example, this conceptual (re)construction would involve the student constructing an explanatory model more similar to the theory of natural selection that, among other things, would include a recognition of the role of chance in the emergence of heritable variants. Although we do not explore this question in more depth due to space limitations, we suggest that the theoretical framework of modeling offers a particularly useful perspective for thinking about how to carry out this conceptual reconstruction (see Svoboda and Passmore 2013). Identification refers to students' ability to recognize what the obstacle is and its multiple expressions (that is, the specific conceptions based on the obstacle, such as the idea of adaptative individual transformation).

It is necessary to clarify that the three aspects of the didactic work on epistemological obstacles (destabilization, conceptual reconstruction, and identification) do not represent three sequential steps of a linear process. Although there is a certain temporal logic (for example, students often begin by favoring the explicitness and destabilization of the obstacle), the three aspects interact continuously. For example, a new concept such as "random character of mutation" becomes a conceptual tool that allows a student to revise his or her conceptions, including the teleological obstacle, from a new perspective.

Aspects (a) and (b) greatly converge with what is proposed in the theoretical framework of conceptual change (Strike and Posner 1992; Vosniadou 2008). Given the recognition that obstacles never disappear (Astolfi 1997b) (statement consistent with the analysis of cognitive psychology, according to which teleological bias is an important functional aspect of normal cognition), the focus of the teaching proposal shifts from the intention of eliminating teleological reasoning to regulating it through metacognition. Although some models of conceptual change place great importance on metacognition (see Gunstone and Mitchell 2005 and Sinatra and Pintrich 
2003), in general, they preserve the "eliminationist" objective that we renounce.

It is important to note that the students' initial model consists of a set of related conceptions (individual transformation, inheritance of acquired characteristics, etc.) about evolution. Some of them involve incorrect forms of teleology. According to our proposal, teleology (in its broadest sense) is an aspect that will be present in both the initial and final models, as well as in the scientific reference model (natural selection). The objective is then a transformation (not a total replacement) of the initial model towards one closer to the scientific one, which implies both the abandonment of some specific conceptions and, eventually, the permanence of others. As we pointed out, in any case, some form of teleology will always persist. In this sense, for the students, one of the goals of "destabilization" is to question unacceptable forms of teleology. Later we point some criteria for distinguishing acceptable and unacceptable forms of teleology.

The main objective would then be for students to develop metacognitive vigilance of the obstacle. Being able to perform such "vigilance" involves (1) being aware of the teleological reasoning, i.e., knowing what this type of reasoning is; (2) being able to identify teleological reasoning, i.e., recognize the multiple expressions of teleological reasoning, which are not always evident; and (3) regulating the obstacle based on a theory, i.e., restricting the use of teleological reasoning by assessing the acceptability of each case with the theory of natural selection as a reference. Thus, the development of these skills represents three key goals of teaching. It is worth mentioning that these skills are not independent: it is not possible to identify expressions of teleological thinking (2) without knowing about the form of thought (1). Likewise, regulating the use of teleological reasoning (3) is not possible if one is unable to identify its expressions (2). Exercising this vigilance would imply both metacognitive knowledge (aspect 1 ) and metacognitive regulation (aspects 2 and 3 ). Therefore, it is an ambitious learning goal that requires hard, long-term work.

As we have mentioned, we suggest that the criterion for determining the acceptability (or unacceptability) of a given teleological expression should be its coherence (or incoherence) with the reference scientific theory (in this case, the theory of natural selection). When the topic discussed in class relates to the evolutionary explanation of adaptations, this criterion would imply that expressions for which teleological reasoning relates to the reasons why the variant of the observed trait was selected would be acceptable. Thus, for example, the expression "white bears were selected in the Artic because that color serves to help them blend in with the environment" could be considered acceptable, even though it is teleological. This idea could also be expressed in the form: the white fur "has the function to help them to blend in with the environment". Since, as we explain later, we consider that the notion of function is itself teleological (McLaughlin 2003) and this last expression would imply an acceptable form of teleology. On the other hand, expressions that relate teleological reasoning with the origin of the variants or with the evolutionary process as a whole should be considered erroneous. Thus, expressions such as "in the arctic, bears mutate to camouflage" would be considered erroneous. Another form of teleology that is unacceptable is assuming that the evolutionary process as a whole follows predetermined directions. In this sense, the idea that the appearance of certain species (typically the human being) is an inevitable result of evolution is an unacceptable form of teleology. Finally, in any of these cases, the student could assume that there is a certain intentionality involved in the evolutionary process, which should always be considered unacceptable because intentionality is not part of the reference theory (natural selection). In summary, adopting consistency with the theory of natural selection as the ultimate criterion of acceptability, we suggest the following general scheme to distinguish acceptable forms of teleology from those that are not:

Acceptable forms of teleology.

- Any teleological expression (in terms of utility, advantage or function) that refers to the reasons why a certain variant of a trait was selected.

Unacceptable forms of teleology.

- Any teleological expression that refers to the inheritable variants appears with a purpose associated with the adjustment of the organism to the environment or its survival.

- Any teleological expression that refers to a predetermined direction in the evolutionary process as a whole.

- Any teleological expression that supposes some form of intentionality guiding the evolutionary process.

It is necessary to point out that the teleological notion of "necessity", frequently indicated as intrinsically incorrect, could appear in any of the mentioned cases (both in the acceptable and in the not acceptable).

The main idea that we defend here is that the recognition that certain forms of teleology persist in biology forces to distinguish the different forms of teleology and to establish an acceptability criterion. The categorization just outlined is not, of course, the only possible one. 
The distinction made by Kampourakis (2020) between "design teleology" and "natural selection teleology"which we have already mentioned- can also function as an adequate theoretical reference to distinguish between acceptable and unacceptable forms of teleology. Lastly, we must not lose sight of the fact that linguistic expressions are usually ambiguous and that, therefore, many times the expressions of the students cannot be considered immediately correct or incorrect. Thus, it will often be necessary to ask students to clarify what they meant by this or that expression, which will help students become aware of the need to express themselves accurately".

\section{Guidelines for the design of activities based on our proposal}

Here, we offer some guidelines and suggestions on the kinds of activities that can be implemented to address the three proposed objectives. Of course, a teacher will only be able to guide this learning process for his or her students if he or she has previously experienced the process. Thus, versions adjusted to the corresponding educational level of this type of activity can be used both in the teaching of biology in secondary school and in teacher education programs so that future teachers have a high degree of understanding of what teleology is and how to teach evolution (or biology in general) so that students' teleological intuition does not hinder the process.

Regarding the first aim (knowing what teleological reasoning is), it is generally necessary for the teacher to introduce the concept of teleology with a simple definition and some pragmatic, clear and self-evident examples. We suggest using a broad definition to capture and discuss the great diversity of related notions associated with teleology (purpose, goal, objective, function, etc.). In this sense, it could be agreed in the class that all the arguments that imply any of these notions will be considered teleological. We believe that it is better to adopt a broad definition of this style and not a more technical and restricted definition, for example, one according to which only those explanations that imply intentionality will be considered teleological. A definition that is too limited could set aside some notions, such as "function," whose teleological character may not be evident, but which would still be important to analyze.

Regarding the problem of which definition of teleology to adopt in class, we suggest that it might be useful to offer students a list of keywords that function as indicators of teleological reasoning. These terms would include "end", "goal", "aim", "purpose", "need", "utility" and "function". However, in addition, taking up Ruse's analysis, it might be useful to propose that students reflect on their own thoughts to detect when they are thinking about organisms or their parts as if they were design objects. Finally, students must understand that language is ambiguous and that interpretations depend on context (for example, we can allow ourselves to use certain teleological expressions that abbreviate speech when we know that the public has a background knowledge that will allow them to avoid misinterpretations, while in other cases we will have to be more careful with our language), so in class, there must be a climate that encourages the expression of implicit ideas and discussion of the meaning and scientific adequacy of any ambiguous expression (the discussion of the scientific adequacy of a specific teleological expression is directly linked to the third objective: the regulation of the obstacle).

In relation to the second aim (identification), it is useful to propose that students identify other examples of teleology in different contexts, such as texts, movies, and documentaries. It is important to discuss examples related to different topics with students, which will help them to abstract the concept beyond specific examples. Expressions such as "John got up early to see the sunrise", "flowers produce a scent in order to attract pollinators" and "dolphins have a hydrodynamic form to swim better" are clear examples of teleology concerning very different subjects. It is also very useful to analyze historical sources, such as the writings of Darwin, who frequently resorted to teleological language and explicitly defended its use (see Lennox 1993), arguing its metaphorical nature (a detailed proposal on how to work from this case can be seen in González Galli 2014). It is also convenient for the teacher to provide examples that become gradually more complex, where the teleological assumption is less explicit and evident. For instance, let us consider the following expressions: (a) "the bacteria mutated because they aimed to become resistant to the antibiotic," (b) "the bacteria mutated to become resistant to the antibiotic," and (c) "the bacteria mutated because otherwise, the antibiotic would have killed them". All three expressions are teleological and, in this case, scientifically incorrect. However, the teleological nature of these expressions is not equally clear for someone who has yet to develop a clear concept of teleology. In case (a), there is an explicit reference to an objective, while in cases (b) and (c), the objective is implicit, being less evident in (c) than in (b).

The third objective (regulation) implies that students are able to identify teleology in their own reasoning and productions, as well as in that of other people. In all cases, students should also be able to assess the scientific adequacy of the identified forms of teleology. To develop this ability, it is necessary to increase the number of occasions in which it is discussed why a particular expression is acceptable or not. When students become involved in this type of analysis, they not only learn what teleology 
is but also improve their understanding of the theory. This is because discussing whether a given expression is consistent with the theory forces students to discuss what exactly the theory says about the world.

To facilitate vigilance of teleological obstacles, it may be useful to use external elements of symbolic support. An example of this type of support is a poster hanging on the walls of the classroom with a phrase such as "Beware of teleology!" These symbolic objects help students be more attentive towards the appearance of obstacles in different moments of the class and facilitate recurring discussions on the subject (Astolfi and Peterfalvi 1997).

\section{Summary and discussion}

We have based this work on the analysis of the philosophy of biology and cognitive psychology to, in line with other recent analyses, argue that completely eliminating students' teleological thinking is neither possible nor desirable. We have reviewed studies of some authors that suggest that explanations of adaptation based on natural selection are teleological or at least that the construction of those explanations requires students to turn to the design metaphor beforehand. The design metaphor, which has clear teleological connotations, involves analyzing organisms as if they were objects deliberately designed to survive in their corresponding environments. We have also discussed the virtues that, from an educational point of view, stem from this epistemological perspective. Among these virtues, we highlighted the resolution of the apparent contradiction between the explicit negation of teleology and the simultaneous ubiquity of teleological reasoning and language. On the other hand, developments in cognitive psychology suggest that all humans tend to analyze biological phenomena from an "intuitive biology" point of view, for which teleology is one of the fundamental assumptions. Such teleological reasoning would be highly functional due to its heuristic, predictive, and explanatory power.

In terms of our main educational concerns, we characterized teleological thinking as an "epistemological obstacle" given its transversal, functional, and potentially conflicting nature in certain learning situations. Considering this theoretical framework, we argued that it would be desirable for students to be able to carry out assessments by using natural selection theory as a "theoretical referee" to help them decide whether specific teleological explanations are scientifically acceptable.

The discussion about which forms of teleology are acceptable and which are unacceptable should not be limited to classes dedicated to the theory of evolution. Given that teleology is a crucial part of "intuitive biology" (Inagaki and Hatano 2006), instances of teleological reasoning will continuously surface in biology class.
For example, teleological conceptions emerge not only in relation to evolution but also in relation to functional analyses in the study of anatomy and physiology (Richardson 1990). Because the design metaphor that underlies the adaptive perspective in evolutionary biology also underlies the functional attributions that are carried out in other areas of biology, such as anatomy and physiology, the type of regulation we propose as an objective would also be necessary in these disciplines. One possible way to relate both areas (evolutionary biology and functional biology) would be to adopt an etiological concept of function (see, for example, Godfrey-Smith 1993). In that case, consistency with natural selection would continue to be the criterion for regulating teleological reasoning. For example, it would not be acceptable to attribute the function of generating pleasure in humans to the scent of a flower because this could not be the reason why that feature was selected. In this way, there should be multiple opportunities to discuss what is meant by any teleological expression and whether that expression is scientifically acceptable.

We understand that the type of teaching work we suggest can be understood as complementary to that stipulated in proposals centered around conceptual change, which is more focused on the generation of cognitive conflicts, evidence analysis, etc. (Kampourakis 2014; Sinatra et al. 2008). Concerning these types of proposals, it is difficult to describe the change in teleological bias that is being sought as a conceptual change. Following what was suggested in this work, the teleological bias should not be modified but rather controlled.

As with any learning related to metacognition, the proposed aim represents an ambitious goal that will require long-term, highly demanding cognitive work. The high level of abstraction is not the only difficulty of attempting to foster a learning experience of this type. Another significant challenge is overcoming a perspective of teleological errors that, even today, is very frequent in the classroom.

In short, students should understand that while certain teleological expressions may be wrong (because they are not consistent with the theory of natural selection), others may be correct. For this reason, the teleological cognitive bias on which both incorrect and correct expressions are based is in itself neither correct nor incorrect. However, this idea clashes with students' tendency to evaluate every way of thinking as either correct or incorrect in absolute terms. Thus, in the case of the explanation of adaptation, both (scientifically erroneous) preinstructional conceptions and conceptions most similar to scientific theory would share a teleological assumption in a broad sense. 
In relation the focus of this paper, much like Evans and Rosengren (2018) point out, intuitive teleological reasoning may serve as a bridge between preinstructional models and models that more closely adhere to scientific theory. This is something that we, the teachers, should bear in mind; moreover, it is something that, from a metacognition perspective, students should be aware of. In our role as education researchers, we recognize that future in-depth investigations are required for a better evaluation of these issues.

As shown in our analysis, there are continuities and discontinuities between intuitive and scientific thinking. Therefore, for instance, we could assume that the teleological reasoning expressed in the question, "How does trait X benefit its holder?", is an aspect shared by biologists and non-biologists, while an ability to rely on the theory of natural selection to "monitor" that reasoning and make it a starting point for the construction of a scientific hypothesis would indicate a discontinuity between biologists and non-biologists. The differences among both systems of thought can be understood in terms of the theory of dual processing of cognition (Evans and Stanovich 2013; Evans and Rosengren 2018; Thompson 2009). According to this theory, there is an intuitive, fast, unconscious type of reasoning and, on the other hand, a slow, conscious, and deliberative type of reasoning. Scientific thinking would be related to this second type of reasoning. The theory of dual processing assumes that learning is not a linear process but a process that involves a complex interaction between both systems of thought. In accordance with Evans and Rosengren (2018), students' intuitive teleology (these authors speak of "teleological realism") would represent the first type of system of thought, while a restricted form of teleology based on a technical notion of biologic purpose would represent the second type of system of thought. We understand this analysis to be coherent with our proposal that teleology constitutes a shared aspect between both systems of thought. Therefore, it is possible that learning the theory of natural selection (and other theories of biology), as well as its use to explain certain phenomena, demands metacognitive reasoning that requires a specific form of interaction between the two thinking systems. Such interaction requires, according to our analysis, the use of a scientific theory (natural selection) to monitor the way in which a component (teleology) present in the intuitive thinking system appears (in a different way) in the scientific thinking system. This perspective of the role of students' intuitive teleology in the process of learning immediately suggests that one of the main teaching aims could be facilitating students' development of the regulation ability. This interpretation follows the metacognition research showing that one of the main differences between experts and beginners lies in the metacognitive skills that allow experts to consciously regulate their cognitive processes (Veenman 2012).

A distinctive aspect of our approach is the explicit acknowledgment of the teleological nature of explanations derived from natural selection theory. This aspect poses some specific issues, for instance, the question of whether the development of "metacognitive vigilance" in the case of natural selection learning necessarily requires an explicit discussion in class on the teleological nature of explanations based on that theory. Such an analysis would involve a level of abstraction that would be difficult in a typical high-school class.

We recognize that future research is necessary to evaluate the scope and limitations of our proposal. In any case, we hope that the ideas discussed here stimulate these investigations and contribute to improving the teaching of evolutionary biology.

\section{Acknowledgements \\ Many thanks to the anonymous referee for their helpful comments.}

\section{Authors' contributions}

LGG: study design, analysis and writing of manuscript. GP: study design, writing of manuscript. AAGG: study design and editing of manuscript. All authors read and approved the final manuscript.

\section{Authors' information}

Leonardo González Galli has a PhD in Biological Science and M.Ed. in Biology Education of Secondary and Higher Education from the Buenos Aires University. He is Research Assistant for the National Council of Scientific and Technological Research (CONICET) and Assistant Professor of Didactics of Biology at the CeFIEC Institute of the Buenos Aires University. His current line of research is focused on the problems of learning and teaching models of evolutionary biology, a subject on which he has published numerous journal articles and book chapters; he has taught lectures and teacher training courses.Gastón Pérez has a Degree (Licentiate) plus Master equivalent from Buenos Aires University as a Teacher in Biology at Middle and University Level. He also has a Diploma in Teaching of Sciences (FLACSO). He is currently working on his $\mathrm{PhD}$ in Science Education and Learning financed by the National Council of Scientific and Technological Research (CONICET). His current line of research is focused on the teaching of evolution from modeling and metacognition on epistemological obstacles. He's a high-school teacher and a teaching assistant at UBA, where he teaches didactics applied to teaching biology. He has given many workshops for teachers, has authored numerous book chapters on didactic proposals for biology teachers and he published some publications in academic journals.Alma Adrianna Gómez Galindo is professor in the Center for Research and Advanced Studies of the National Polytechnic Institute (Cinvestav) in Monterrey, México. She has a degree as teacher of early childhood education, is a marine biologist and has a PhD in didactics of science. She performs qualitative research on biology education, focusing in teaching - learning sequences for modeling by using multimodal representations and analogies. Her current projects include the analysis of dialogic perspectives for teaching evolution in cultural diversity contexts and developing of learning progressions for central models in biology to guide learning from kindergarten to middle school.

\section{Funding}

This research was supported by the National Council of Scientific and Technological Research (CONICET) and the University of Buenos Aires (UBA), No. UBACYT 20020170200330BA.

Availability of data and materials

All de-identified results, protocols, and resources are reported herein or in supplemental information. 


\section{Competing interests}

The authors declare that they have no competing interests.

\section{Author details}

${ }^{1}$ Instituto de Investigaciones CeFIEC, Facultad de Ciencias Exactas y Naturales de la Universidad de Buenos Aires, Consejo Nacional de Investigaciones Científicas y Técnicas (CONICET), Pablo Abriata 2371, San Isidro, Boulogne Sur Mer, Provincia de Buenos Aires 1609, Argentina. ${ }^{2}$ Facultad de Ciencias Exactas y Naturales de la Universidad de Buenos Aires, Intendente Güiraldes 2160 Ciudad Universitaria, Buenos Aires, Provincia de Buenos Aires 1428, Argentina. ${ }^{3}$ Unidad Monterrey, Cinvestav, Vía del conocimiento 201, Km. 9.5 Carretera nueva al aeropuerto, Parque PIIT, Apodaca, Nuevo León 66600, México.

Received: 16 July 2019 Accepted: 16 April 2020

Published online: 30 April 2020

\section{References}

Allen C, Bekoff M, Lauder G. Introduction. In: Allen C, Bekoff M, Lauder G, editors. Nature's purposes. analyses of function and design in biology. Cambridge: The MIT Press; 1998a. p. 1-25.

Allen C, Bekoff M, Lauder G. Nature's purposes. Analyses of function and design in biology. Cambridge: The MIT Press; 1998b.

Anderson D, Fisher K, Norman G. Development and evaluation of the conceptual inventory of natural selection. J Res Sci Teaching. 2002. https://doi. org/10.1002/tea.10053.

Arriew A. Teleology. In: Hull D, Ruse M, editors. The Cambridge companion to philosophy of biology. New York: Cambridge University Press; 2007. p. 160-81.

Astolfi JP. Mots clés de la didactique des sciences. Paris: De Boeck \& Larcier; $1997 a$.

Astolfi JP. L'erreur, un outil pour enseigner. Montruge: ESF Éditeur; 1997b.

Astolfi JP, Develay M. La didactique des sciences. París: Presses Universitaires de France; 1989.

Astolfi JP, Peterfalvi B. Stratégies de travail des obstacles: dispositifs et resorts. Aster Recherchers en didactique des sciences expérimentales. 1997;25:193-216.

Aubusson P, Harrison A, Ritchie S. Metaphor and analogy in science. Dordretch: Springer; 2006.

Ayala F. Teleological explanations in evolutionary biology. Philos Sci. 1970;37(1):1-15

Bardapurkar A. Do students see the "selection" in organic evolution? a critical review of the causal structure of student explanations. Evol Edu Outreach. 2008. https://doi.org/10.1007/s12052-008-0048-5.

Bartov $\mathrm{H}$. Teaching students to understand the advantages and disadvantages of teleological and anthropomorphic statements in biology. J Res Sci Teaching. 1981;18(1):79-86.

Berg J, Tymoczko J, Gatto G Jr, Stryer L. Biochemistry. 8th ed. New York: H. D. Freem and company; 2015.

Bishop B, Anderson C. Students conceptions of natural selection and its role in evolution. J Res Sci Teaching. 1990;27(5):415-27.

Boekaerts M. Self-regulated learning: where we are today. Int J Edu Res. 1999. https://doi.org/10.1016/s0883-0355(99)00014-2.

Bradie M. Science and metaphor. Biol Philos. 1999;14(2):159-66.

Branch G, Scott E. Estratagemas del creacionismo. Investigación y. Ciencia. 2009;388:74-81.

Brandon R. Biological teleology: questions and explications. Stud Hist Philos Sci. 1981;12(2):91-105.

Brandon R. Adaptation and environment. Princeton: Princeton University Press; 1990.

Carey S. On the origin of causal understanding. In: Sperber D, Premak D, Premak A, editors. Causal cognition: a multidisciplinary debate. New York: Oxford University Press; 1995. p. 268-308.

Coley J, Tanner K. Common origins of diverse misconceptions: cognitive principles and the development of biology thinking. CBE Life Sci Educ. 2012. https://doi.org/10.1187/cbe.12-06-0074.

Cross D, Paris S. Developmental and instructional analyses of children's metacognition and reading comprehension. J Educ Psychol. 1988. https:// doi.org/10.1037/0022-0663.80.2.131.
Dawkins R. Climbing mount improbable. New York: W. W. Norton \& Company; 1996.

Dennett D. The Intentional Stance. Cambridge: The MIT Press; 1989.

Dennett D. Darwin's dangerous idea: evolution and the meanings of life. Nueva York: Simon and Schuster; 1995.

Dennett D. From bacteria to bach and back. The evolution of minds. New York: WW. Norton \& Company; 2017.

Dye K, Stanton J. Metacognition in upper-division biology students: awareness does not always lead to control. CBE Life Sci Edu. 2017. https://doi. org/10.1187/cbe.16-09-0286.

Evans E. Bridging the gap: from intuitive to scientific reasoning - The case of evolution. In: Rutten K, Blancke S, Soetaert R, editors. Perspectives on science and culture. West Lafayette: Purdue University Press; 2018. p. 251-306.

Evans E, Rosengren K. Cognitive biases or cognitive bridges? intuitive reasoning in biology. In: Kampourakis K, Reiss M, editors. Teaching biology in schools global research, issues, and trends. New York: Routledge; 2018. p. 9-21.

Evans J, Stanovich K. Dual-Process Theories of higher cognition: advancing the debate. Perspectives Psychol Sci. 2013;8(3):223-41.

Futuyma D. Evolution. Sunderland: Sinauer; 2009.

Gelman S, Rhodes M. Two-thousands years of stasis: how psychological essentialism impedes evolutionary understanding. In: Rosengren K, Brem S, Evans $E$, Sinatra $G$, editors. Evolution challenges Integrating research and practice in teaching and learning about evolution. England: Oxford University Press; 2012. p. 3-21.

Gelman R, Williams E. Enabling constraints for cognitive development and learning: domain specificity and epigenesis. In: Kuhn D, Siegler R, editors. Handbook of child psychology: Cognition, perception and language. New York: John Wiley; 1998. p. 575-630.

Ghiselin M. Darwin's language may seem telelological, but his thinking is another matter. Biol Philos. 1994;9(4):489-92.

Ghiselin M. The triumph of Darwinian method. New York: Dover Publications; 2003.

Giere R. Explaning Science. A Cognitive Approach. Chicago: The University of Chicago Press; 1988.

Godfrey-Smith P. Functions: consensus without Unity. Pacific Philos Quart. 1993. https://doi.org/10.1111/j.1468-0114.1993.tb00358.x.

Godfrey-Smith P, Sterelny K. Biological Information. In: Zalta E, editor. The Stanford Encyclopedia of Philosophy. 2008

González Galli L. "Darwin teleólogo"y "el eclipse del darwinismo": dos casos para repensar la historia del evolucionismo. In Quintanilla Gatica M, Daza Rosales S, Cabrera Castillo H (Comp). Historia y filosofía de la ciencia. Aportes para una 'nueva aula de ciencias', promotora de ciudadanía y valores. Santiago de Chile: Bellaterra. Sociedad Chilena de Didáctica, Historia y Filosofía de la Ciencia. 2014;266-84.

González Galli L, Meinardi E. The role of teleological thinking in learning the Darwinian model of evolution. Evol Edu Outreach. 2011;4(1):145-52.

González Galli L, Meinardi E. Obstáculos para el aprendizaje del modelo de evolución por selección natural, en estudiantes de escuela secundaria de Argentina. Ciência \& Educação. 2015;21(1):101-22.

Gould S, Lewontin R. The spandrels of San Marco and the Panglossian paradigm: a critique of the adaptationistprogramme. Proc Royal Soc London B. 1979;205(1161):581-98. https://doi.org/10.1098/rspb.1979.0086.

Gregory R. Understanding natural selection: essential concepts and common misconceptions. Evol Edu Outreach. 2009. https://doi.org/10.1007/ s12052-009-0128-1.

Gresch H, Martens M. Teleology as a tacit dimension of teaching and learning evolution: a sociological approach to classroom interaction in science education. J Res Sci Teaching. 2019;56(3):243-69.

Gunstone R, Mitchell I. Metacognition and conceptual change. In: Harlen W, editor. Teaching Science for Understanding. San Diego USA: Academic Press; 2005. p. 134-63.

Hacker D, Dunlosky J, Graesser A. Handbook of Metacognition in Education. New York: Routledge; 2009.

Haydock K, Arunan M. Teaching and Learning about Evolution and Natural Selection: Problems and Solutions. episteme-5 International conference to review research on Science, TEchnology and Mathematics Education, Proceedings, HomiBhabha Centre for Science Education. 2003; 106-112. 
Hickman C, Roberts L, Keen S, Larson A, L'Anson H. Integrated principles of zoology. Boston: McGraw-Hill; 2008.

Inagaki K, Hatano G. Young children's conception of the biological world. Curr Directions Psychol Sci Thousand Oaks. 2006;15(4):177-81.

Jacob F. The Logic of Life. A History of Heredity. Princeton: Princeton University Press; 1993.

Jungwirth E. Caveat mentor—Let the teacher beware. Res Sci Edu. 1975a. https://doi.org/10.1007/bf02558620.

Jungwirth $E$. The problem of teleology in biology as a problem of biology teacher education. J Biol Edu. 1975b. https://doi.org/10.1080/00219 266.1975.9654037.

Kallery M, Psillos D. Anthropomorphism and animism in early years science: why teachers use them, how they conceptualise them and what are their views on their use. Res Sci Edu. 2004;34(3):291-311.

Kampourakis K. Students teleological misconceptions in evolution education: why the underlying design stance, not teleology per se, is the problem. Evolu Edu Outreach. 2020. https://doi.org/10.1186/s12052-019-0116-z.

Kampourakis K. Understanding evolution. Nueva York: Cambridge University Press; 2014.

Kampourakis K, Palaiokrassa E, Papadopoulou M, Pavlidi V, Argyropoulou M. Children's intuitive teleology: shifting the focus of evolution education research. Evol Edu Outreach. 2012;3:4-5.

Kampourakis K, Zogza V. Students' intuitive explanations of the causes of homologies and adaptations. Sci Educ. 2008;17(1):27-47.

Keil F. The birth and nurturance of concepts by domains: The origins of concepts of living things. In: Hirschfeld L, Gelman S, editors. Mapping the mind Domain specificity in cognition and culture. Cambridge: Cambridge University Press; 1994. p. 234-54.

Kelemen D. Function, goals and intention: children's teleological reasoning about objects. Trends Cognit Sci. 1999a;3(12):461-8.

Kelemen D. The scope of teleological thinking in preschool children. Cognition. 1999b;70:241-72.

Kelemen D. Teleological minds: How natural intuitions about agency and purpose influence learning about evolution. In: Rosengren K, Brem S, Evans E, Sinatra G, editors. Evolution challenges. Integrating research and practice in teaching and learning about evolution. Inglaterra: Oxford University Press; 2012. p. 66-92.

Kelemen D, Rottman J, Seston R. Professional physical scientists display tenacious teleological tendencies. Purpose-based reasoning as a cognitive default. J Exp Psychol. 2013;142(4):1074-83.

Kleiner S. Explanatory coherence and empirical adequacy: the problem of abduction, and the justification of evolutionary models. Biol Philos. 2003; 18:513-27.

Legare C, Gelman S. Bewitchment, biology, or both: the co-existence of natural and supernatural explanatory frameworks across development. Cognit Science. 2008. https://doi.org/10.1080/03640210802066766.

Lennox J. Darwin was a teleologist. Biol Philos. 1993;8:409-21.

Lennox J. Teleology by another name: a replay to Ghiselin. Biol Philos. 1994;9(4):493-5.

Lennox J, Kampourakis K. Biological teleology: the need for history. In: Kampourakis K, editor. The Philosophy of Biology: a Companion for Educators. Dordrecht: Springer; 2013. p. 421-54.

Lewens T. Function talk and the artefact model. Stud History Philos Biol Biomed Sci. 2000;31(1):95-111.

Lewens T. Organisms and Artifacts Design in Nature and Elsewhere. Cambridge: The MIT Press; 2004.

Lewontin R. Adaptation. Sci Am. 1978;239(3):212-29.

Lorenz K. The Foundations of Ethology. New York: Springer; 1982.

Mahner M, Bunge M. Foundations of Biophilosophy. Berlin: Springer Verlag; 1997.

Mayr E. Toward a new philosophy of biology. Cambridge: Harvard University Press; 1988.

Mayr E. One Long Argument. Charles Darwin and the Genesis of Modern Evolutionary Thought. Cambridge: Harvard University Press; 1991.

Mayr E. This is Biology. The Science of the Living World. Cambridge: Harvard University Press; 1997.

Mayr E. What Makes Unique Biology. Considerations on autonomy of a scientific discipline. Cambridge: Cambridge University Press; 2004.

McLaughlin P. What functions explain. Functional explanation and self-reproducing system. Cambridge: Cambridge University Press; 2003.
Miller-Friedmann J, Sunbury S, Sadler P. Inequitable Foundations? Educational Equality in Evolution. In: Harms U, Reiss M, editors. Evolution education re-considered understanding what works. Dordrecht: Springer; 2019. p. 101-15.

Nagel E. The structure of science. problems in the logic of scientific explanation. New York: Harcourt Brace and World; 1961.

Nehm R, Schonfeld I. Does increasing biology teacher knowledge of evolution and the nature of science lead to greater preference for the teaching of evolution in schools? J Sci Teacher Educ. 2007. https://doi.org/10.1007/ s10972-007-9062-7.

Peña-Ayala A, Cárdenas L. A conceptual model of metacognitive activity. In: Peña-Ayala A, editor. Metacognition: Fundaments, Applications and Trends A Profile of the Current State-of-the-Art. Heidelberg: Springer; 2015. p. 39-64.

Peterfalvi B. Enseignants et élèves face aux obstacles. Aster. Recherchers en didactique des sciences expérimentales. 1997;25:193-216.

Pittendrigh C. Adaptation, natural selection, and behavior. In: Roe A, Simpson G, editors. Behavior and Evolution. New Haven: Yale University Press; 1958.

Richardson D. A survey of students' notions of body function as teleologic or mechanistic. Am J Physiol. 1990;258(6):8-10.

Rottman J, Zhu L, Wang W, Seston Schillaci R, Clark KJ, Kelemen D. Cultural influences on the teleological stance: evidence from China. Religion Brain Behavior. 2016;7(1):17-26. https://doi.org/10.1080/21535 99x.2015.1118402.

Ruse M. Teleology: yesterday, Today, and Tomorrow? Stud Hist Philos Biol Biomed Sci. 2000;31(1):213-32.

Ruse M. Darwin and design. Does evolution have a purpose?. Cambridge: Harvard University Press; 2003.

Ruse M. Charles Darwin. Malden: Balckwell; 2008.

Schachner A, Zhu L, Li J, Kelemen D. Is the bias for function-based explanations culturally universal? Children from China endorse teleological explanations of natural phenomena. J Exp Child Psychol. 2017;157:29-48.

Schickore J. Scientific Discovery. The Stanford Encyclopedia of Philosophy: Stanford University; 2018.

Schraw G. Promoting general metacognitive awareness. Instr Sci. 1998. https:// doi.org/10.1023/a:1003044231033.

Schraw G, Crippen K, Hartley K. Promoting self-regulation in science education: metacognition as part of a broader perspective on learning. Res Sci Educ. 2006. https://doi.org/10.1007/s11165-005-3917-8.

Settlage J. Conceptions of natural selection: a snapshot of the sense-making process. J Res Sci Teaching. 1994;31(5):449-57.

Short T. Teleology in nature. Am Philos Q. 1983;20(4):311-9.

Short T. Darwin's concept of final cause: neither new nor trivial. Biol Philos. 2002;17(3):322-40.

Sickel AJ, Friedrichsen P. Examining the evolution education literature with a focus on teachers: major findings, goals for teacher preparation, and directions for future research. Evolu Educ Outreach. 2013;6(1):23.

Simpson G. This view of life. Nueva York: Harcourt, Brace and World; 1964.

Sinatra G, Brem S, Evans M. Changing Minds? implications of conceptual change for teaching and learning about biological evolution. Evolu Edu Outreach. 2008;1(2):189-95.

Sinatra G, Pintrich P. Intentional Conceptual Change. Mahwah: Lawrence Erlbaum Associates Publishers; 2003.

Smith M. Current status of research in teaching and learning evolution: i. philosophical/epistemological issues. Sci Educ. 2010a;19(4-8):523-38.

Smith M. Current Status of research in teaching and learning evolution: II, Pedagogical Issues. Sci Educ. 2010b;19(4-8):523-38.

Sober E. Philosophy of Biology. New York: Routledge; 2000.

Sober E. Conceptual issues in evolutionary biology. Massachusetts: The MIT Press; 2006

Stamos D. Evolution and the big questions. Sex, Race and other Matters. Malden: Blackwell; 2008

Sterelny K, Griffiths P. Sex and Death. An Introduction to Philosophy of Biology. Chicago: The University Chicago Press; 1999.

Strike K, Posner G. A revisionist theory of conceptual change. In: Duschl R, Hamilton R, editors. Philosophy of Science, Cognitive Psychology, and Educational Theory and Practice. Albany: Suny; 1992.

Svoboda J, Passmore C. The strategies of modeling in biology education. Sci Educ. 2013;22:119-42. 
Talanquer V. On cognitive constraints and learning progressions: the case of "structure of matter". Int J Sci Educ. 2009;31(15):2123-36.

Tamir P, Zohar A. Anthropomorphism and teleology in reasoning about biological phenomena. Sci Educ. 1991;75(1):57-67.

Thompson VA. Dual-process theories: A metacognitive perspective. In: Evans J, Frankish K, editors. In two minds: Dual processes and beyond. Oxford: Oxford University Press; 2009. p. 171-96.

Veenman M. Metacognition in science education: definitions, constituents, and their intricate relation with cognition. In: Zohar A, Dori Y, editors. Metacognition in science education. Trends in current research. Dordrecht: Springer; 2012. p. 21-36.

Vosniadou S. International handbook of research on conceptual change. New York: Routledge; 2008.

Walsh D. Chasing shadows: natural selection and adaptation. Stud History Philos Sci. 2000;31(1):135-53.

Walsh D. Organisms as natural purposes: the contemporary evolutionary perspective. Stud History Philos of Biol Biomed Sci. 2006;37(4):771-91.

Working Group on Teaching Evolution. Teaching about evolution and the nature of science. Washington: National Academy Press; 1998.
Williams G. Adaptation and natural selection; a critique of some current evolutionary thought. Princeton: Princeton University Press; 1966.

Wilson D. Evolution for Everyone. How Darwin's Theory Can Change the Way We Think About Our Lives. New York: Delacorte Press; 2007.

Zohar A, Barzilai S. A review of research on metacognition in science education: current and future directions. Stud Sci Edu. 2013. https://doi. org/10.1080/03057267.2013.847261.

Zohar A, Dori Y. Metacognition in science education trends in current research. Dordretch: Springer; 2012.

Zohar A, Ginossar S. Lifting the taboo regarding teleology and anthropomorphism in biology. Educ Heretical Suggest Sci Educ. 1998;82(6):679-97.

Zimmerman B. Attaining self-regulation: a social cognitive perspective. In: Boekaerts M, Pintrich P, Zeidner M, editors. Handbook of Self-Regulation. Burlington: Elsevier Academic Press; 2000. p. 13-39.

\section{Publisher's Note}

Springer Nature remains neutral with regard to jurisdictional claims in published maps and institutional affiliations.
Ready to submit your research? Choose BMC and benefit from:

- fast, convenient online submission

- thorough peer review by experienced researchers in your field

- rapid publication on acceptance

- support for research data, including large and complex data types

- gold Open Access which fosters wider collaboration and increased citations

- maximum visibility for your research: over $100 \mathrm{M}$ website views per year

At BMC, research is always in progress.

Learn more biomedcentral.com/submissions 